\title{
International Survey on Criteria for Training and Accredita- tion in Interventional Neuroradiology
}

\author{
Yunsun Song, $\mathrm{MD}^{1}$, Minjae Kim, $\mathrm{MD}^{1}$, Michael Söderman, $\mathrm{MD}^{2}$, Dae Chul Suh, $\mathrm{MD}^{1}$, \\ René van den Berg, $\mathrm{MD}^{3}$ \\ ${ }^{1}$ Department of Radiology, Asan Medical Center, University of Ulsan College of Medicine, Seoul, Korea \\ ${ }^{2}$ Department of Clinical Neuroscience, Karolinska Institutet and Department of Neuroradiology, Karolinska University Hospital, Solna, Sweden \\ ${ }^{3}$ Department of Radiology and Nuclear Medicine, Amsterdam University Medical Centers (AMC), Amsterdam, The Netherlands
}

Purpose: With the rapid expansion of the field of interventional neuroradiology (INR) and the diverse background of aspiring neuro-interventionists, there is an ever increasing need to establish consensus criteria for training and accreditation in INR.

Materials and Methods: We performed a survey to explore the current state of criteria for training and accreditation in INR. The questionnaire consisting of 11 questions was emailed to the members of World Federation of Interventional and Therapeutic Neuroradiology (WFITN) worldwide. It was focused on the training charter, training program, qualifying examination, and education after training program as perceived by practitioners in each country.

Results: A total of 52 WFITN members in 19 countries responded to the questionnaire. There was a huge variation internationally and nationally due to the unique situation and challenges in each country and institution. Criteria for training and accreditation in INR were well established in some countries of Europe, North America, and Asia but not specified in other countries.

Conclusion: It is critical to establish consensus criteria for training and accreditation in INR in order to ensure safe practice and continued expansion and development of INR as a specialty.

Key Words: Interventional neuroradiology; Accreditation; Training; Medical education

\section{INTRODUCTION}

In recent years the field of interventional neuroradiology (INR) has been rapidly expanding with the development of devices and increasing demand for minimally invasive surgery. Endovascular treatment of stroke in patients with large vessel occlusions has gained wide acceptance worldwide with a concomitant increase in workload. The aspiring and practicing neuro-interventionists have increased in number, coming from diverse backgrounds ranging from radiology and neurology to neurosurgery. In many countries there is no formal training. In addition, in such a rapidly changing situation, previously established training programs, examinations and continuous education may be inadequate.

There have been many efforts to establish criteria for training and accreditation in Europe and North America. The first attempt to propose guidelines regarding the training in INR was done

\section{Correspondence to: René van den Berg, MD \\ Department of Radiology and Nucle- ar Medicine, Amsterdam University Medical Centers (AMC), Meibergdreef 9, 1105 AZ Amsterdam, The Nether- lands \\ Tel: +31207324352 \\ Fax: +31205669655 \\ E-mail: r.vdberg@amsterdamumc.nl}

Received: December 19, 2019

Revised: March 19, 2020

Accepted: March 20, 2020
Copyright $\odot 2020$ Korean Society of Interventional Neuroradiology

This is an Open Access article distributed under the terms of the Creative Commons Attribution Non-Commercial License (http://creativecommons.org/licenses/by-nc/4.0) which permits unrestricted non-commercial use, distribution, and reproduction in any medium, provided the original work is properly cited.

pISSN 2093-9043 eISSN 2233-6273 
in 1998 following the foundation of the World Federation of Interventional and Therapeutic Neuroradiology (WFITN)., ${ }^{1,2}$ This was followed by many medical associations publishing their own charters or requirements for INR including the proposed Union of European Medical Specialists (UEMS) Division of Neuroradiology Training Charter and United States Accreditation Council for Graduate Medical Education (ACGME) program requirements for endovascular surgical neuroradiology. Despite these efforts, appropriate INR training programs have not yet been established in many countries, and there may be a lack of awareness of the existence or necessity of such systems. To ensure patient safety it is imperative that adequate training and quality assurance are in

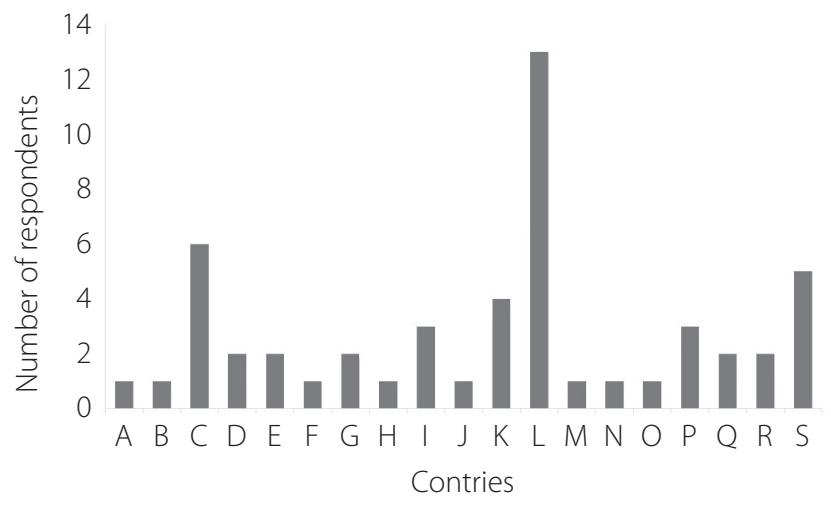

Fig. 1. Number of respondents in each country. Total of 52 World Federation of Interventional and Therapeutic Neuroradiology members in 19 countries. The letters on the $x$-axis represent each country included in the survey.

Individual

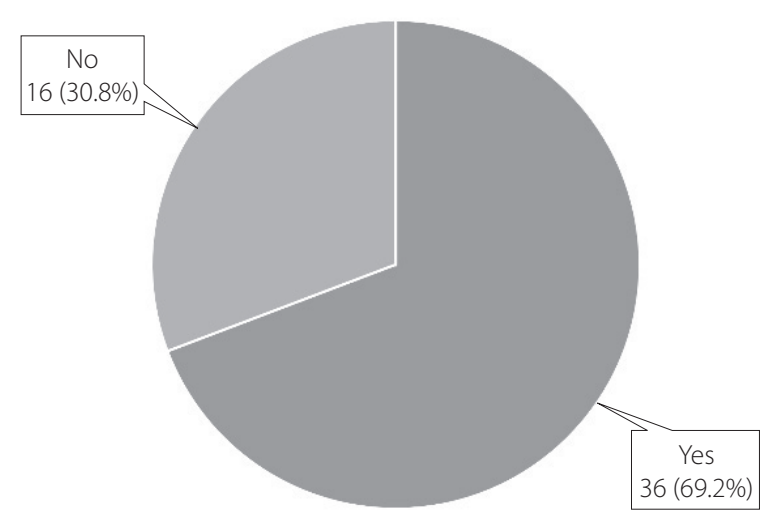

Yes No Mixed place. We conducted an international survey to explore the current state of criteria for training and accreditation in INR.

\section{MATERIALS AND METHODS}

\section{Survey}

This survey on training in INR was send to all members of the WFITN in preparation for a meeting organized by the WFITN on "Accreditation in Neurolntervention". The participants were asked to answer 11 questions included in this questionnaire (Supplementary Table 1). The results of the questionnaire were analyzed per country and per region.

\section{RESULTS}

\section{Participants}

Total of 52 WFITN members in 19 countries responded to the questionnaire (Fig. 1). The country names were replaced with alphabets in random order. These included five from the Americas (North-Middle-South), eight from Europe, one from South Africa, and five from Asia.

\section{Training charter for expertise in INR}

The presence of a training charter for expertise in INR and whether it is in accordance with the guidelines of the WFITN is shown in Fig. 2. Out of the 52 responders, 36 (69.2\%) re-

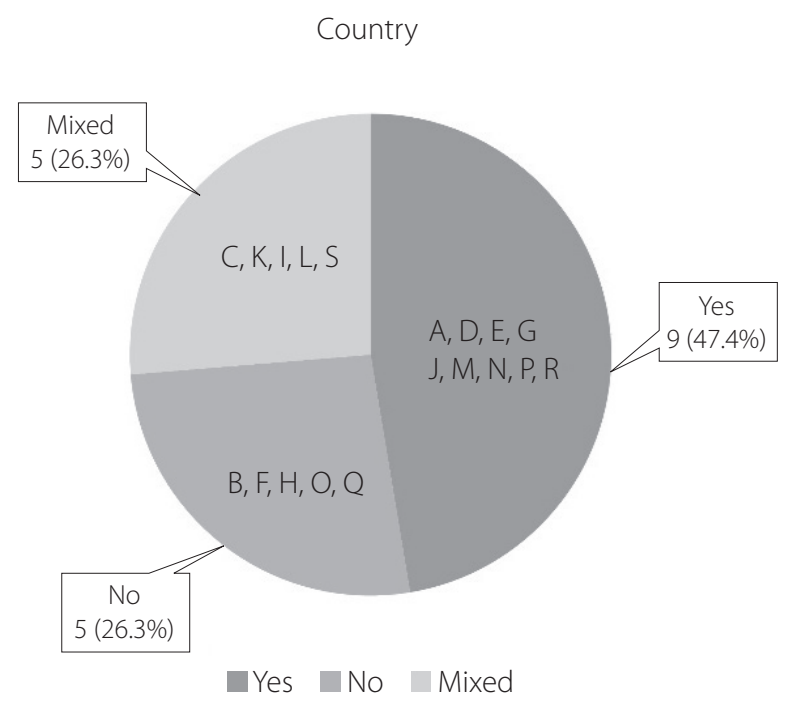

Fig. 2. Presence of training charter for expertise in interventional neuroradiology in accordance with the guidelines of the World Federation of Interventional and Therapeutic Neuroradiology. 
ported that the training charter was present in his or her country and they were from 9 countries including $A, D, E, G$, $J, M, N, R$, and P. No training charters were recognized in $B$, $F, H, O$, and $Q$. Participants from $C, I, K, L$, and $S$ gave mixed response regarding the presence of a training charter.

Out of the 36 who acknowledged the presence of a training charter, 34 indicated that the training charter was in accordance with the guidelines of the WFITN. Nine participants indicated that the training charter was in accordance with the guidelines of the WFITN (E, P, and R). The majority of the participants $(n=23,67.6 \%)$ indicated that the training charter was partially in accordance with the guidelines of the WFITN and two participants (5.9\%) indicated that the training charter was not. The discrepancy was seen in terms of length of the training program with shorter training program reported by 11 participants and contents of the training program reported by 9 participants.

\section{Training program}

Thirty-four of the 52 responded to questions regarding the training program (Fig. 2). The contents of the training program consisted of clinical neurology $(n=28,82.4 \%)$, neurovascular anatomy $(n=32,94.1 \%)$, knowledge and treatment of stroke $(n=32,94.1 \%)$, aneurysm $(n=32,94.1 \%)$, arteriovenous malformation (AVM)/dural arteriovenous fistula (DAVF) ( $n=31$, $91.2 \%)$, vascular spinal malformations $(n=27,79.4 \%)$, percutaneous spinal disc herniations ( $n=8,23.5 \%)$, tumor embolization ( $n=28,82.4 \%$ ) and pediatric interventional radiology $(n=20,58.8 \%)$. The training programs were in accordance with the WFITN training charter in the majority of responses.

$B, C, N$, and $O$ had no national training program (Fig. 3). This was offered in $E, F, G, L, P, R$, and $S$. It was executed in all training centers in $23.5 \%(n=8)$, majority of centers in $32.4 \%(n=11)$ and minority of centers in $5.9 \%(n=2)$.

Thirteen participants reported the presence of an institution or board for quality control of the training program in four countries ( $F, L, R$, and $S)$.

\section{Examination for accreditation}

The official examination for INR after completion of training was reported to be undertaken by $50.0 \%$ of participants $(n=17)$ from $B, E, F, G, I, L, N, O$, and R. Amongst these, there was an official written examination in four countries $(n=15)$ and official practical examination in five countries $(n=15)$. Participants from $C, D, H$, and $P$ reported that there was no official examination for INR after completion of training ( $n=17$, $50.0 \%)$

\section{Continuous medical education}

Out of 34 participants, 19 participants (55.9\%) reported that there was a national regulatory body ensuring continuous medical education in ten countries (C, D, F, G, J, L, N, P, and S).

\section{DISCUSSION}

This international survey exploring the current state of criteria for training and accreditation in INR revealed that there

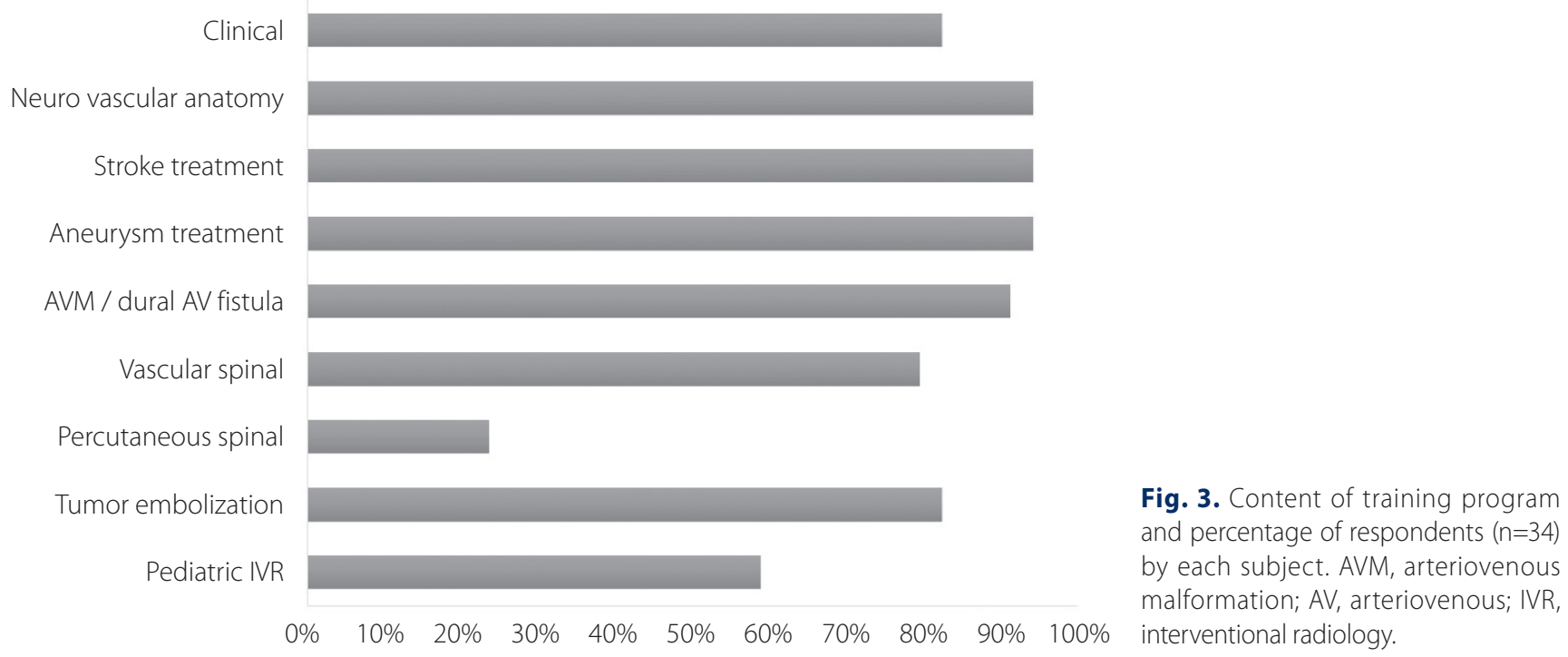


was a huge variation internationally and nationally due to the unique situation and challenges in each country and also at an institutional (hospital) level. Criteria for training and accreditation in INR were well established in some countries of Europe, North America and Asia but not specified in other countries. In addition, there was a discrepancy in the answers received from the same country reflecting the lack of consensus guidelines and awareness pertaining to the issue of training and accreditation in INR.

The UEMS Division of Neuroradiology formulated a training charter for training in INR. The final document was a product of 5 specialties (neurology, neurosurgery, cardiology, radiology, and neuroradiology) working together to accomplish a common goal to establish a clear definition of INR as a particular competence open to physicians from all specialties after sufficient training. This was made possible by cooperation, compromises with mutual acceptance and agreement among peers. ${ }^{3}$ The text of the Training Charter in INR was finalized in December 2010, but unfortunately was never formally approved by the UEMS council. It has since been adopted by the WFITN, European Society of Minimally Invasive Neurological Therapy and other societies as a training charter. This is in contrast to for example the United States ACGME program for INR which is restricted to specialists in Radiology, Neurology and Neurosurgery and is based on only 1 year of graduate training in endovascular surgical neuroradiology. In our survey, participants from E and R acknowledge the presence of a local training charter and reported that it was in accordance with the UEMS writing. In $G$ and $N$, the main discrepancy is related to the length of training. Despite the efforts by the UEMS, participants from $B$, $\mathrm{O}$, and $\mathrm{Q}$ reported the lack of a national training charter.

Since Zhao et al. ${ }^{4}$ reported differences in medical education system and requirements for training in INR in China, Japan, and Korea, an accreditation program for neuro-interventionists as well as hospitals in Korea has started in 2015 by the Korean Society of Neurointervention. There are 165 certified members and 57 hospitals up to 2019. Japan established a specialist qualification system for INR in 1997 with the first examination held in 2002. Both Japan and China have an official charter specifying the length and content of the training program. In particular, INR training was open to all specialties in Japan and had the detailed specification in terms of qualification as a specialist or consulting subspecialist. The training charter in Japan required the highest number of cases specified categorically (aneurysms, AVM or DAVF, revascularization and tumors) separately as an operator or assistant. Moreover, the qualification examination entailed written, oral and practical examination with pass rate of 50\% to $60 \%$. In this international survey, there were 13 responders from Japan but no participants from China or Korea.

There were several limitations in this study. First, the questionnaire was sent to all WFITN members but only 52 members from 19 countries participated in the survey. The low response rate (about 10\%) might be related to the way the questionnaire was delivered to WFITN members. One of the co-authors of this study, who is an active member of WFITN, was not aware of this survey and could therefore not respond. The format of the survey and the way the survey was conducted may not have been easily accessible to some members of WFITN. It might have been that the survey was considered SPAM and was either deleted automatically or only reached the SPAM box. Also in cases where more than one WFITN member worked in the same institution they may feel it sufficient with only one answer.

Considering the international set-up of the survey, a future survey should again be performed online, but in order to increase participation apart from emails a separate message should be posted on the official website from the WFITN. Second, there was a discrepancy in the answers received from within a single country. This may raise questions on the reliability of the answers and understanding of the participants, although members of WFITN, are with the training national training charters. Hence, it was difficult to assess the actual situation related to training and accreditation in countries with mixed responses. However, this may, in turn, reflect the lack of consensus guidelines and awareness pertaining to the issue of training and accreditation in INR in such countries. It seems necessary to check with the official governing body (if present), with regards to the criteria for training and accreditation.

\section{CONCLUSION}

This international survey explored the current state of criteria for training and accreditation in INR and revealed a huge variation internationally and nationally. This emphasizes the urgent need for consensus criteria for training and accreditation particularly considering the rapid expansion of the field of INR and the diverse background of neurointerventionists in training. There is a need to provide guidelines and to sup- 
port the established international consensus criteria. These have to be adapted to the unique situation and challenges in each separate country.

\section{SUPPLEMENTARY MATERIAL}

Supplementary material related to this article can be found online at https://doi.org/10.5469/neuroint.2019.00283.

\section{Acknowledgments}

We thank Dr. Shigeru Miyachi for his comments.

\section{Fund}

None.

\section{Ethics Statement}

This is a non-patient related survey for which no ethical stament is required.

\section{Conflicts of Interest}

The authors have no conflicts to disclose.

\section{Author Contribution}

Concept and design: RvdB and MS. Analysis and interpretation: RvdB, MS, DCS, and YS. Data collection: RvdB. Writing the article: YS, RvdB, MS, MK, and DCS. Critical revision of the article: YS, RvdB, MS, MK, and DCS. Final approval of the article: YS, RvdB, MS, MK, DCS. Statistical analysis: RvdB. Obtained funding: none. Overall responsibility: RvdB.

\section{ORCID}

Yunsun Song: https://orcid.org/0000-0003-4738-0533

Minjae Kim: https://orcid.org/0000-0002-5382-9360

Michael Söderman: https://orcid.org/0000-0003-3642-3702

Dae Chul Suh: https://orcid.org/0000-0003-1561-5596

René van den Berg: https://orcid.org/0000-0002-8791-8791

\section{REFERENCES}

1. Lasjaunias P. Editorial. What is the role of the WFITN with regards to the worldwide clinical practice of Interventional and Therapeutic NeuroRadiology, its world meeting and scientific challenges (research)? Interv Neuroradio/ 2007;13:311-313

2. Picard L. Interventional neuroradiology training charter. Interv Neuroradiol 2009;15:11-15

3. Flodmark O, Grisold W, Richling B, Mudra H, Demuth R, Pierot L. Training of future interventional neuroradiologists: the European approach. Stroke 2012;43:2810-2813

4. Zhao LB, Miyachi S, Shi HB, Suh DC. Comparison of medical education and requirements for training in the interventional neuroradiology in China, Japan and Korea. Neurointervention 2013;8:3-8 